\title{
Volatiles from Subtropical Convolvulaceae That Interfere with Bacterial Cell-to-Cell Communication as Potential Antipathogenic Drugs
}

\author{
María C. Luciardi, ${ }^{1}$ María V. Pérez Hernández, ${ }^{1}$ Nora Muruaga, ${ }^{2}$ Alicia Bardón, ${ }^{1,3}$ \\ Mario E. Arena, ${ }^{1,3}$ and Elena Cartagena ${ }^{1}$ \\ ${ }^{1}$ Instituto de Química Orgánica, Facultad de Bioquímica, Química y Farmacia, Universidad Nacional de Tucumán, \\ Ayacucho 471, 4000 Tucumán, Argentina \\ ${ }^{2}$ Fundación Miguel Lillo, Miguel Lillo 251, 4000 Tucumán, Argentina \\ ${ }^{3}$ INQUINOA-CONICET, Ayacucho 471, 4000 Tucumán, Argentina
}

Correspondence should be addressed to Elena Cartagena; ecartagena@fbqf.unt.edu.ar

Received 21 March 2016; Revised 22 April 2016; Accepted 27 April 2016

Academic Editor: Daniela Rigano

Copyright (C) 2016 María C. Luciardi et al. This is an open access article distributed under the Creative Commons Attribution License, which permits unrestricted use, distribution, and reproduction in any medium, provided the original work is properly cited.

\begin{abstract}
Increasing chronic bacterial infections create an urgent need for new antimicrobial agents or strategies for their control. Targeting virulence is one of the alternative approaches to find new medicines to treat persistent infections due to bacteria with biofilmphenotype which are more resistant to antibiotics than their planktonic counterparts having an extreme capacity for evading the host defences. A bioguided study of sixteen extracts from flowers and leaves of four subtropical Convolvulaceae species provided evidence of the occurrence of antipathogenic natural products active against Gram positive and negative bacteria. Particularly, volatile metabolites from Merremia dissecta creeper, a food and medicinal plant, were able to interfere with the Pseudomonas aeruginosa quorum sensing system by a strong decrease of $N$-acyl homoserine lactone (AHL) biosynthesis (63$75 \%$ ), which attenuated the virulence factor expression like biofilm (55\%) and elastase activity (up to 27\%), key factors that enable the colonization and dissemination of the infection in the host. Control of the P. aeruginosa biofilm and the QS process by phytochemicals, such as (+) spathulenol, isolated from a bioactive extract of $M$. dissecta leaves would be a good strategy for the development of new and effective antipathogenic drugs.
\end{abstract}

\section{Introduction}

Microbes like bacteria can coordinate gene expression as a community through the secretion and detection of signalling molecules so that its members can simultaneously express specific behaviors. This mechanism of regulation, called quorum sensing (QS), seems to be a key trait for adaptation to specific environments and has been shown to regulate a variety of important phenotypes in the production of virulence factors like biofilm and proteolytic enzymes, crucial factors that enable colonization and dissemination of the infection in the host. Persistent and chronic bacterial infections have been directly linked to the presence of microbial biofilms. Microbial biofilms are sessile communities of one or more microorganisms that reside within a self-produced extracellular matrix. These cellular aggregates can form on living and nonliving surfaces, soluble and insoluble materials, are fairly ubiquitous in natural ecosystems, and have serious implications to human health. The inherent characteristic of microbial biofilms is a remarkable tolerance to treatment with antibiotics traditionally effective against planktonic (free floating) bacteria [1-4].

Biofilm infections, such as pneumonia in cystic fibrosis patients, chronic wounds, chronic otitis media, and implant and catheter associated infections, affect millions of people in the developed world each year and many deaths occur as a consequence [5]. 
There is evidence that bacterial QS process is involved in cross-kingdom signalling with eukaryotic organisms, mainly plants, that are capable of producing compounds that can interfere with QS systems in bacteria by inhibiting QS signal biosynthesis, which leads to attenuation of virulence factor expression [6]. Our investigations take inspiration from nature's models and attempts to design solutions to the problem of microbial biofilms [7-11].

Medicinal plants have become part of complementary medicine worldwide, because of their potential health benefits. Various plant extract has great potential against infectious agents and can be used for therapeutic purposes [12].

Convolvulaceae is a large family comprising about 58 genera and 1650 species of herbs, climbers, or shrubs distributed in tropical and subtropical regions [13]. The greatest species diversity occurs in the Americas and Africa. The family can be recognized by their funnel-shaped radially symmetrical corollas. The leaves and tuberous roots of some species are used as foodstuffs, and the seeds are exploited for their medicinal value as purgatives. Some species contain ergoline alkaloids that are likely responsible for the use of these species as ingredients in psychedelic drugs. The presence of ergolines in some species of this family is due to infection by fungi related to the ergot fungi of the genus Claviceps. The morning glory family is a rich source of bioactive compounds such as polyketides, terpenoids, steroids, flavonoids, coumarins, alkaloids, cyanogenic glycosides, and other compounds [14-16].

Several antibacterial activity studies of Convolvulaceae species and only a few about antibiofilms effects were previously published [17-22]. Therefore, this investigation presents a bioguided study of Ipomoea cairica, I. nil, I. purpurea, and Merremia dissecta that led to the discovery of plant volatiles that interfere with the Pseudomonas aeruginosa QS system, by declining of the QS signal production which attenuates virulence factor expression like biofilms and elastase $B$ activity. In vitro antibiofilm effects against Staphylococcus aureus are also reported for the first time in this paper.

\section{Materials and Methods}

2.1. Collection and Identification of Plant Materials. Leaves and flowers of Ipomoea cairica (L.) Sweet, I. nil (L.) Roth, I. purpurea (L.) Roth, and Merremia dissecta (Jacq.) Hallier f. (Convolvulaceae) were collected during the flowering stage in March, road to Villa Nougués $\left(26^{\circ} 51^{\prime} 28.08^{\prime \prime} \mathrm{S}\right.$, $65^{\circ} 22^{\prime} 32.16^{\prime \prime} \mathrm{W}$ ), Tucumán province, Argentina. Their identities were confirmed by Dr. Nora Muruaga and voucher specimens (LIL 610.873, 610.871, 610.870, and 610.872, resp.) were deposited at the Herbarium of Fundación Miguel Lillo, Tucumán, Argentina.

2.2. Preparation of Plant Extracts. The fresh plant material (leaves or flowers, $25 \mathrm{~g}$ ) was extracted at room temperature for 3 days with small volume of diethyl ether (twice). The extracts from flowers and leaves were dried in rotary evaporator (Büchi R-3000) under vacuum at $30^{\circ} \mathrm{C}$ to give the following extracts: diethyl ether extracts from flowers (DEF) and leaves (DEL) and methanol extracts from flowers (MEF) and leaves (MEL).
2.3. Ultraviolet-Visible (UV-Vis) Analysis. UV-Vis spectra were measured in ethanol using a Shimadzu UV-Vis 160 A spectrophotometer in the range $200-800 \mathrm{~nm}$ to detect chromophoric systems with pharmacological potential.

\subsection{Preliminary Screening to Select a Promising Bioactive Extract}

2.4.1. Effects of Plant Extracts on Bacterial Growth. Overnight cultures of $P$. aeruginosa ATCC 27853 and Staphylococcus aureus ATCC $6538 \mathrm{P}$ were diluted to reach $2.5 \times 10^{6} \mathrm{CFU} / \mathrm{mL}$ in Luria-Bertani (LB) and Mueller Hinton medium, respectively. The diluted culture $(190 \mu \mathrm{L})$ was placed in each of the 96 wells of a microtitre polystyrene plate. Solutions containing $0.1 \mathrm{mg} / \mathrm{mL}$ of extracts in DMSO- $\mathrm{H}_{2} \mathrm{O}(50: 50)$ were prepared separately and $10 \mu \mathrm{L}$ of each was pipetted to the plastic microtitre plate wells individually (8 replicates). Control wells (8 replicates) contained the diluted culture $(190 \mu \mathrm{L})$ and $10 \mu \mathrm{L}$ of a solution of DMSO- $\mathrm{H}_{2} \mathrm{O}(50: 50)$ in which the final concentration of DMSO was $2.5 \%$. Medium control was prepared using sterile LB (or $\mathrm{MH}$ ). Bacteria were cultured in LB (or $\mathrm{MH}$ ) medium at $37^{\circ} \mathrm{C}$ and growth was detected as turbidity $(600 \mathrm{~nm}$ or $560 \mathrm{~nm})$ using a microtitre plate reader (Power Wave XS2, Biotek, VT, USA) and by direct counting of $\mathrm{CFU} / \mathrm{mL}$ determined by plating $0.1 \mathrm{~mL}$ of the inoculation onto LB agar ( $\mathrm{pH}$ 6.0). The maximum level of DMSO to which the cells were exposed was $2.5 \%$.

2.4.2. Antibiofilm Effects. For biofilm quantification, a micromethod based on a protocol previously reported was employed [23]. Biofilms formed after $24 \mathrm{~h}$ incubation of bacterial cultures prepared as described in the previous paragraph were stained with $20 \mu \mathrm{L}$ of an aqueous solution of crystal violet $(0.1 \%, \mathrm{w} / \mathrm{v})$ for $20 \mathrm{~min}$. After washing with water, the liquid was discarded from the wells and the material that remained fixed to the polystyrene (containing biofilm) was washed with PBS (thrice). Crystal violet bound to biofilm was removed from each well employing $200 \mu \mathrm{L}$ absolute ethanol during $30 \mathrm{~min}$ at $37^{\circ} \mathrm{C}$ with shaking. Absorbance $(540 \mathrm{~nm})$ of ethanol solutions of crystal violet was determined using a microtitre plate reader (Power Wave XS2, Biotek, VT, USA). Azithromycin $(5 \mu \mathrm{g} / \mathrm{mL})$, a known quorum sensing inhibitor, was incorporated in the bioassay as a control in the same experimental conditions employed to evaluate the compounds [24].

2.5. GC-EIMS and Isolation of Main Compound from a Bioactive Extract. On the basis of antibacterial and antibiofilm properties an extract among sixteen was selected and analyzed by gas chromatography techniques. GC-EIMS was carried out using a Thermo Electron Trace ${ }^{\mathrm{TM}}$ Ultra couple with split-split less injector and Polaris Q instrument (Thermo Scientific, TX, USA) ion trap mass spectrometer equipped with a DB-5 capillary column $(30 \mathrm{~m} \times 0.25 \mathrm{~mm}$, film thickness $0.25 \mu \mathrm{m})$. The initial temperature of the column was $60^{\circ} \mathrm{C}$ during $0 \mathrm{~min}$. A temperature programming was applied from $60^{\circ} \mathrm{C}$ to $246^{\circ} \mathrm{C}$ at a rate flow of $3^{\circ} \mathrm{C} / \mathrm{min}$ and finally $280^{\circ} \mathrm{C}$ for $15 \mathrm{~min}$. Carrier gas was helium (flow 
$1 \mathrm{~mL} / \mathrm{min})$. Split injection mode is $1 / 10$. The identification of volatile components was based on computer matching with the NIST08 GC/MS library and by comparison of the mass spectra, retention times (RT), and Kovats retention indexes (RI) with those reported in the literature [25].

2.6. Chromatography Techniques. Diethyl ether extract from leaves of $M$. dissecta (DEL, $1 \mathrm{~g}$ ) were fractionated on silica gel (70-230 Mesh, 1:50 w/w) column chromatography employing petroleum ether and increasing amounts of EtOAc $(0-100 \%)$ and finally $\mathrm{MeOH}$ as mobile phase. The fourteen fractions were monitored by TLC on aluminium-precoated silica gel plates (Merck, Kieselgel $60 \mathrm{~F}_{254}$ ). The spots on the plates were visualised under UV light, and the plates were then sprayed with Godin reagent.

Fraction 4 isolated from DEL with a yield of $7.18 \%$ (according to Section 3) was submitted to GC-EIMS analysis and the main volatile compounds were determined. Then, this fraction was rechromatographed with more silica gel ratio $(1: 100, w / w)$ to give a known sesquiterpene whose NMR and EIMS spectra were measured.

2.7. Antibacterial and Antibiofilm Activities of M. dissecta Fractions. The bacterium screened was a biofilm phenotypic variant of Pseudomonas aeruginosa ATCC 27853, and the medium and techniques employed were previously described.

2.8. Antielastase $\beta$ Activity of $M$. dissecta Fractions. Elastolytic activity was determined using a modification of the method previously described [26]. The substrate of the enzyme $\beta$-elastase, elastin Congo red $(100 \mu \mathrm{L})$ (Sigma), was dissolved in Tris- $\mathrm{HCl}(\mathrm{pH} 8.0)$ at a concentration of $5 \mathrm{mg} / \mathrm{mL}$ and then it was mixed with $100 \mu \mathrm{L}$ of cell-free culture supernatant obtained from $P$. aeruginosa ATCC 27853 grown during $24 \mathrm{~h}$, in LB media containing $5 \mu \mathrm{g} / \mathrm{mL}$ of fractions, respectively. The reaction mixture $(200 \mu \mathrm{L})$ was incubated at $37^{\circ} \mathrm{C}$ for $24 \mathrm{~h}$ and centrifuged at $13,000 \mathrm{rpm}$ for $10 \mathrm{~min}$. The absorbance $(495 \mathrm{~nm})$ of the supernatant is a measure of the enzyme activity.

2.9. Autoinducer (AHL) Quantification. The interruption of bacterial cell-to-cell communication was deduced by autoinducer (AHL) quantification, using $\beta$-galactosidase activity assay. $P$. aeruginosa qsc 119 (reporter strain) is a mutant donated by Dr. Greenberg that cannot produce its own AHL (QS signal molecules). The reporter strain responds, by producing $\beta$-galactosidase, to exogenous active signal molecules generated by wild-type $P$. aeruginosa strains. $P$. aeruginosa qsc 119 was constructed using a chromosomal promoter under the control of AHLs linked to lacZ. In consequence, $\beta$-galactosidase activity is under QS-control and in direct relationship with the AHL activity [27].

An overnight culture of the reporter strain grown at $37^{\circ} \mathrm{C}$ in $\mathrm{LB}$ was diluted ten times in the same medium, reaching values of absorbance of 0.26 at $\mathrm{OD}_{560 \mathrm{~nm}}$. A $100 \mu \mathrm{L}$ portion of this suspension was mixed, in each microplate well, with $100 \mu \mathrm{L}$ cell-free culture supernatant obtained from
P. aeruginosa ATCC 27853 cultured in LB media containing $100 \mu \mathrm{g} / \mathrm{mL}$ of fractions, during $24 \mathrm{~h}$. Azithromycin, known to interfere with the QS process, was used at $5 \mu \mathrm{g} / \mathrm{mL}$, concentration unable to affect the bacterial growth, as QS positive control under the same conditions as fractions [23]. Control wells (8 replicates) contained cell-free culture supernatant $(100 \mu \mathrm{L})$ obtained from $P$. aeruginosa ATCC 27853 cultured in $\mathrm{LB}$ media $(190 \mu \mathrm{L})$ plus $10 \mu \mathrm{L}$ of DMSO- $\mathrm{H}_{2} \mathrm{O}(50: 50)$. $\beta$ galactosidase activity was measured spectrophotometrically by Miller test [28].

2.10. Statistical Analysis. Differences between means were evaluated by analysis of variance (ANOVA). The Tukey test was used for all pair-wise multiple comparisons of groups. In all statistical analysis $P$ values $>0.05$ were not considered significant. Statistix 10 data analysis software for researches (2013) was used.

\section{Results and Discussion}

3.1. UV Absorptions and Yields of Convolvulaceae Extracts. All extracts showed a strong UV absorption $(298-380 \mathrm{~nm})$, a typical feature of the occurrence of aromatic compounds. These results are in agreement with the Convolvulaceae chemistry as it has already mentioned, since these metabolites are well known for their biological and pharmacological potential. It is important to note that the $\mathrm{MeOH}$ extracts (ME) exhibited the highest extraction yields (1.43-3.11\%) reaching $3.11 \%$ in the ME of $I$. nil leaves (Table 1).

3.2. Antibacterial and Antibiofilm Activities of Convolvulaceae Extracts. The diethyl ether extracts (DE) were more active than methanol ones against $P$. aeruginosa growth as shown in Table 1 . The antibacterial activity could be due to the presence of lipophilic compounds with lower polarity than cholesterol (according to TLC profile). This fact suggests that their principal targets are cell membranes and their toxicity would be caused by loss of chemiosmotic control as previously reported [29]. In relation to cell growth of $S$. aureus, the in vitro results demonstrated that both extracts are slightly active (Table 1).

Nevertheless, the addition of small amounts of $\mathrm{MeOH}$ extracts into $P$. aeruginosa cultures produced a lower biofilmbiomass than those of EE, except for $M$. dissecta DEL (diethyl ether extract from leaves) which only allowed a $20 \%$ biofilm formation (Table 1). In addition, this effect was correlated with an important inhibition of bacterial growth. S. aureus biofilm-biomass was also strongly reduced by all extracts (71-100\%), and these effects were not growth dependent. $M$. dissecta MEF (MeOH extract from flowers) gave the best biofilm inhibition (100\%).

3.3. Selection of a Promising Extract for Bacterial Biofilm Control. M. dissecta DEL, which reduced $P$. aeruginosa biofilm by $80 \%$, was selected among sixteen extracts to continue studies. As it is unusual for natural products to be more active against Gram negative than positive bacteria [30], it is very important to find active compounds against pathogenic P. aeruginosa, 


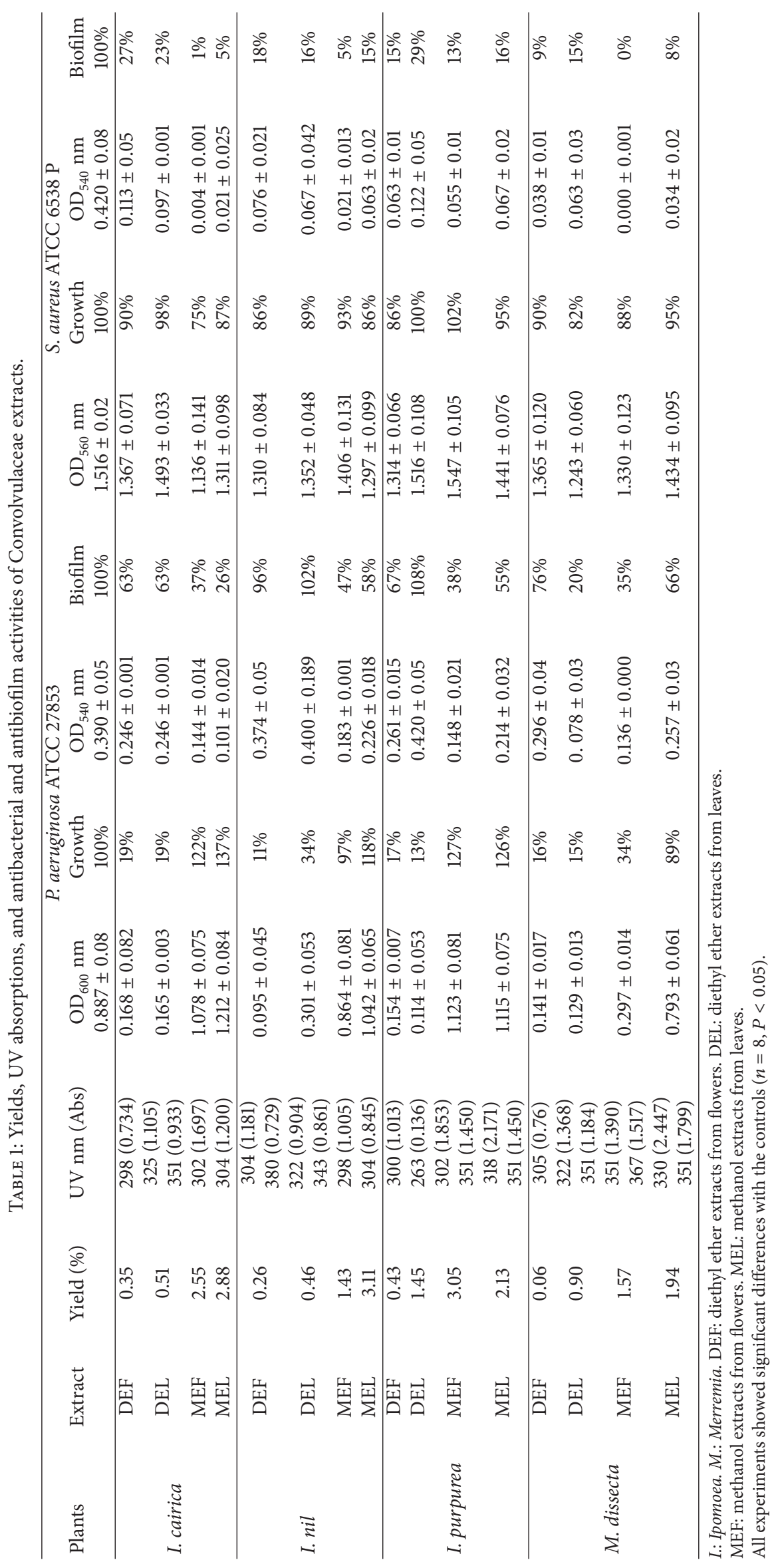


which is a major cause of infection in immune-compromised patients. Indeed, these bacteria can cause serious infections in patients who have received massive antibiotic therapy, suffered severe burns, contracted HIV, or have a genetic disease like cystic fibrosis [31].

$M$. dissecta has been employed traditionally as a condiment, medicine, and ornament by an array of cultures. In Argentina, roots of $M$. dissecta var. edentata are still used as food by a few indigenous groups [16].

3.4. GC-EIMS Profile of M. dissecta Diethyl Ether Extract. GC-EIMS analysis of $M$. dissecta DEL has led to the identification of nine plant volatile compounds (Table 2) such as germacrene D (25.56\%), $\beta$-caryophyllene (13.47\%), spathulenol (6.27\%), $\beta$-elemene (4.70\%), and $\delta$-elemene (2.65\%) (sesquiterpenes), while benzyl alcohol (11.17\%), benzoic acid (3.36\%), and long-chain saturated fatty acids (17.28\%) were also determined. Thus, $M$. dissecta is a promising source of sesquiterpenes and aromatic compounds with important bioactivities.

\subsection{Fractionation of $M$. dissecta Diethyl Ether Extract and} Bioactivities. DEL fractionation yielded fourteen fractions of increasing polarity, and their comparative effects on $P$. aeruginosa growth, biofilm production, and $\beta$-elastase activity (\%) were investigated here. As shown in Figure 1, fractions $1-4$ and 6 inhibit biofilm formation; particularly fraction 4 eluted with petroleum ether-ethyl acetate 95:5 displayed the highest $P$. aeruginosa biofilm inhibition (55\%). Growth and elastolytic activity were inhibited by $31 \%$ and $27 \%$, respectively. Coherently, the specific biofilm produced, that is, the amount of biofilm that each bacterium forms [10] calculated as the relation between the biofilm developed $\left(\mathrm{OD}_{540 \mathrm{~nm}}\right)$ and bacterial growth $\left(\mathrm{OD}_{600 \mathrm{~nm}}\right)$, was lower than control (0.6537).

It is remarkable that fractions 5 and 7-14 showed a strong increase of biofilm formation after $24 \mathrm{~h}$ of incubation, although the $P$. aeruginosa growth was not notably inhibited as most stressors would. This composition-specific behavior is consistent with previous publications that demonstrated that small chemical changes exert opposite effects (inhibition-stimulation) $[8,10]$. According to our previous results $[7,32]$, this important stimulant effect could be exploited to obtain a higher biofilm-biomass of polycyclic aromatic hydrocarbon degrading Pseudomonas that would improve strategies for optimizing the carcinogenic substances bioremediation process.

In addition, the elastolytic activity of $P$. aeruginosa was significantly reduced by all fractions compared to control $(13 \%-28 \%, P<0.05)$.

3.6. Antiquorum Sensing Mode of Action of M. dissecta Fractions. All assayed fractions produced a notable decrease of the $P$. aeruginosa autoinducer biosynthesis (63-75\%). Particularly, fraction 4 showed an AHL activity reduction of $72 \%$ (Figure 2). The observed effects are correlated with the biofilm formation and elastase activity decrease except for fractions 5 and 7-14 that produced more biofilm than

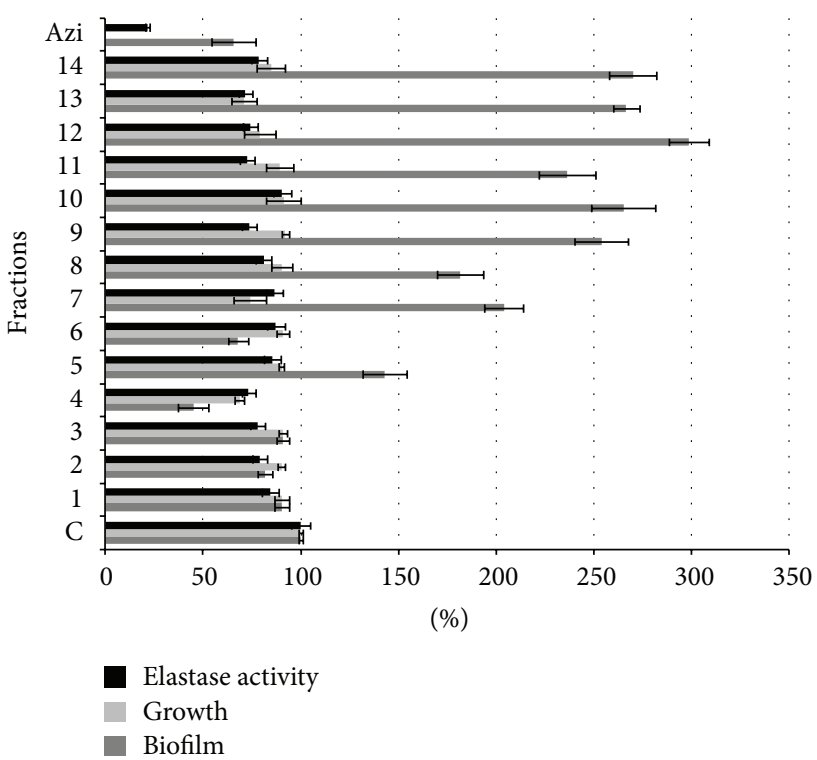

FIgURE 1: Effects of fractions 1-14 from Merremia dissecta on Pseudomonas aeruginosa growth, biofilm production, and elastase activity. Azi: azithromycin, C: Pseudomonas aeruginosa ATCC 27853, and 1-14: fractions of $M$. dissecta diethyl ether extract. The error bars indicate standard deviation $(n=8)$. All experiments showed significant differences with the control $(P<0.05)$.

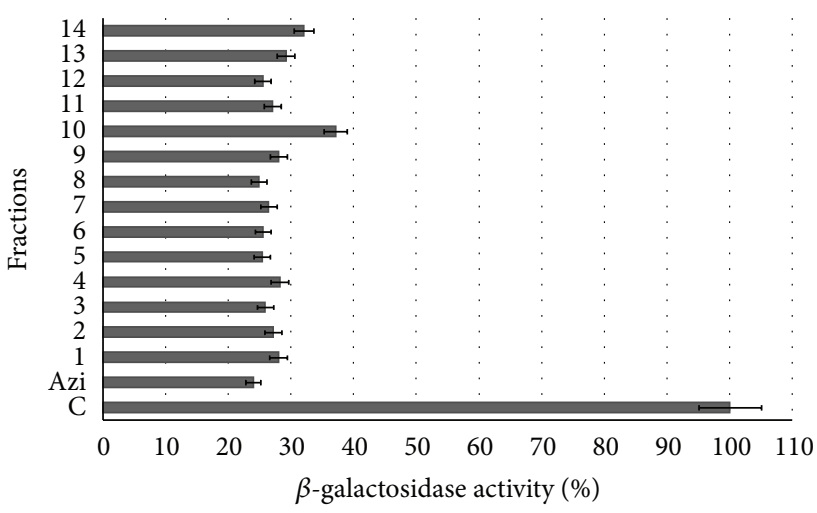

FIGURE 2: Quantification of $N$-acyl homoserine lactones signals by $\beta$-galactosidase activity. Azi: azithromycin supernatant, C: $P$. aeruginosa ATCC 27853 supernatant, and 1-14: fractions of $M$. dissecta diethyl ether extract (supernatants). The error bars indicate standard deviation $(n=8)$. All experiments showed significant differences with the control supernatant $(P<0.05)$.

control (Figure 1). This lack of correspondence could be due to another mechanism involved in biofilm formation.

It is very important to find plant natural products that decrease AHL production, since AHLs are signals utilized by Gram negative pathogenic bacteria to enable host colonization through AHL-mediated inhibition of induced inflammation via innate immune receptor mechanisms [33]. These signalling molecules inhibit lymphocyte proliferation and tumour necrosis factor- $\alpha$ production. They also decrease interleukin-12 production in lipopolysaccharide-stimulated macrophages [34]. 
TABLE 2: Volatile metabolites of $M$. dissecta diethyl ether extract.

\begin{tabular}{|c|c|c|c|c|c|c|}
\hline $\mathrm{RT}^{\mathrm{a}}(\min )$ & $\mathrm{RI}^{\mathrm{b}}$ & Compounds & Structure & $\mathrm{MW}^{\mathrm{c}}$ & $\begin{array}{c}\text { Main mass } \\
\text { fragmentation } \\
\text { peaks }(m / z)\end{array}$ & $\%$ \\
\hline 8.79 & 1036 & Benzyl alcohol & & 108 & $\begin{array}{c}108\left(\mathrm{M}^{+\bullet}\right), 107 \\
91,79(100 \%) \\
63 \text { and } 51\end{array}$ & 11.17 \\
\hline 14.49 & 1150 & Benzoic acid & & 122 & $\begin{array}{c}122\left(\mathrm{M}^{+\bullet}\right), 105 \\
(100 \%), 77 \text { and } \\
51\end{array}$ & 3.36 \\
\hline 20.80 & 1377 & $\delta$-Elemene & & 204 & $\begin{array}{c}204\left(\mathrm{M}^{+\bullet}\right), 189 \\
175,161,148 \\
136,121(100 \%) \\
105,93,77,67 \\
\text { and } 53\end{array}$ & 2.65 \\
\hline 23.16 & 1398 & $\beta$-Elemene & & 204 & $\begin{array}{l}189,147,107,81 \\
(100 \%) \text { and } 68\end{array}$ & 4.70 \\
\hline 24.45 & 1494 & $\beta$-Caryophyllene & & 204 & $\begin{array}{c}204\left(\mathrm{M}^{+\bullet}\right), 189 \\
161,133,105 \\
\text { and } 93(100 \%)\end{array}$ & 13.47 \\
\hline 27.6 & 1515 & Germacrene D & & 204 & $\begin{array}{c}204\left(\mathrm{M}^{+\bullet}\right), 161 \\
(100 \%), 105,79 \\
\text { and } 55\end{array}$ & 25.56 \\
\hline 31.05 & 1536 & Spathulenol & & 220 & $\begin{array}{c}220\left(\mathrm{M}^{+\bullet}\right), 205 \\
187,159,131 \\
119,91(100 \%) \\
79 \text { and } 55\end{array}$ & 6.27 \\
\hline 38.9 & & Not identified & & & & 5.83 \\
\hline 45.6 & 1869 & $\begin{array}{c}\text { Pentadecanoic } \\
\text { acid }\end{array}$ & & 242 & $\begin{array}{c}242\left(\mathrm{M}^{+\bullet}\right), 199 \\
143,129,115,87, \\
73(100 \%), \text { and } \\
60\end{array}$ & 13.52 \\
\hline 45.65 & 2167 & Stearic acid & & 284 & $\begin{array}{c}284\left(\mathrm{M}^{+\bullet}\right), 265 \\
241,185,143, \\
129,115,97,83 \\
73(94 \%) \text { and } \\
57\end{array}$ & 3.76 \\
\hline
\end{tabular}

${ }^{a} \mathrm{RT}$ : retention time. ${ }^{\mathrm{b}} \mathrm{RI}$ : Kovats retention indexes. ${ }^{\mathrm{c}} \mathrm{MW}$ : molecular weight. 


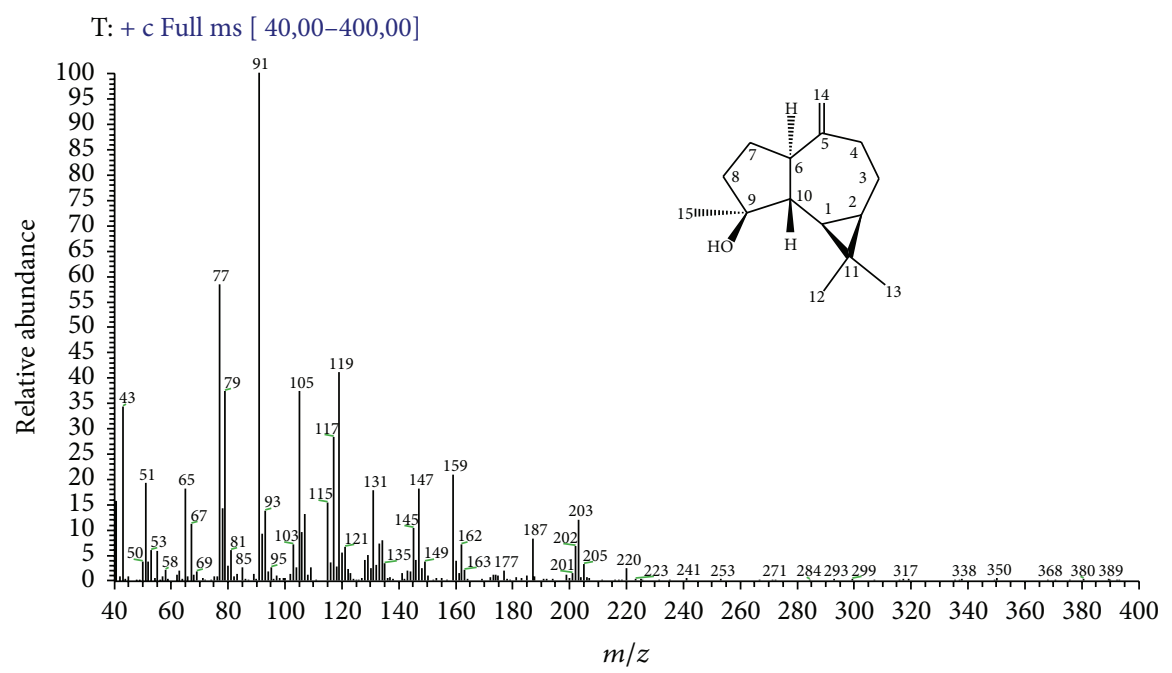

FIGURE 3: EIMS profile of fraction 4 (+ spathulenol) and the assignments of the main mass fragmentation peaks. MS $[\mathrm{m} / z]: 220\left[\mathrm{M}^{\bullet+}\right]$, $205\left[\mathrm{M}-\mathrm{CH}_{3}\right]^{+}, 203[\mathrm{M}-\mathrm{OH}]^{+}, 202\left[\mathrm{M}-\mathrm{H}_{2} \mathrm{O}\right]^{\circ+}, 187\left[\mathrm{M}-\mathrm{CH}_{3}-\mathrm{H}_{2} \mathrm{O}\right]^{+}, 177\left[\mathrm{M}-\mathrm{CH}_{3}-\mathrm{C}=\mathrm{O}\right]^{+}$or $\left[\mathrm{M}-\mathrm{CH}_{3}-\mathrm{CH}_{2}=\mathrm{CH}_{2}\right]^{+}, 163\left[\mathrm{C}_{12} \mathrm{H}_{19}\right]^{+}, 159$ $\left[\mathrm{C}_{12} \mathrm{H}_{15}\right]^{+}, 147\left[\mathrm{C}_{11} \mathrm{H}_{15}\right]^{+}, 145\left[\mathrm{C}_{11} \mathrm{H}_{13}\right]^{+}, 119\left[\mathrm{C}_{9} \mathrm{H}_{11}\right]^{+}, 117\left[\mathrm{C}_{9} \mathrm{H}_{9}\right]^{+}, 105\left[\mathrm{C}_{8} \mathrm{H}_{9}\right]^{+}, 91\left[\mathrm{C}_{7} \mathrm{H}_{7}\right]^{+}(100 \%), 77\left[\mathrm{C}_{6} \mathrm{H}_{5}\right]^{+}, 67\left[\mathrm{C}_{5} \mathrm{H}_{7}\right]^{+}, 65\left[\mathrm{C}_{5} \mathrm{H}_{5}\right]^{+}, 51$ $\left[\mathrm{C}_{4} \mathrm{H}_{3}\right]^{+}$, and $43\left[\mathrm{C}_{3} \mathrm{H}_{7}\right]^{+}$.

3.7. Chemical Composition of the Bioactive Fraction 4. Spathulenol was found in fraction 4 by GC-EIMS and NMR analysis. Indeed, the NMR data of fraction 4 were identical to those previously reported for (+) spathulenol [35], and its EIMS profiling and the assignments of fragment ions are shown here (Figure 3). Hence, these results lead us to suppose that the antipathogenic effects exerted by fraction 4 can be attributed to the occurrence of $(+)$ spathulenol.

In addition, the antibacterial and antipathogenic properties of stereoisomer (-) ent-spathulenol isolated from Porella species were previously demonstrated by Gilabert et al. [8]. However, it is important to note that $(+)$ spathulenol, isolated from leaves of the vascular plant $M$. dissecta, showed a better anti- $\beta$-galactosidase activity than (-) isomer found in liverworts.

\section{Conclusions}

The bioguided study of the subtropical Convolvulaceae species assayed provides evidence of the occurrence of antipathogenic natural products active against Gram positive and negative bacteria. Particularly, eukaryotic metabolites such as (+) spathulenol from the ethnomedicinal plant $M$. dissecta are able to interfere with the Pseudomonas aeruginosa QS system by a strong decrease of the AHL biosynthesis (72\%) which attenuates virulence factor expression.

The biofilm matrix is a key therapeutic target, and our findings suggest that the signalling pathway interruption by natural products of $M$. dissecta could be exploited as a good strategy for the development of new and effective antipathogenic drugs.

\section{Competing Interests}

The authors declare that there are no competing interests regarding the publication of this paper.

\section{Acknowledgments}

The authors wish to thank Professor Dr. Peter Greenberg for providing the $P$. aeruginosa reporter strain and Professor Dr. Juan Carlos Valdez for his help and PIUNT-D-552-1 for its grants.

\section{References}

[1] J. W. Costerton, P. S. Stewart, and E. P. Greenberg, "Bacterial biofilms: a common cause of persistent infections," Science, vol. 284, no. 5418, pp. 1318-1322, 1999.

[2] M. E. Davey and G. A. O’Toole, "Microbial biofilms: from ecology to molecular genetics," Microbiology and Molecular Biology Reviews, vol. 64, no. 4, pp. 847-867, 2000.

[3] P. A. Sokol, C. Kooi, R. S. Hodges, P. Cachia, and D. E. Woods, "Immunization with a Pseudomonas aeruginosa elastase peptide reduces severity of experimental lung infections due to $P$. aeruginosa or Burkholderia cepacia," The Journal of Infectious Diseases, vol. 181, no. 5, pp. 1682-1692, 2000.

[4] P. S. Stewart and J. W. Costerton, "Antibiotic resistance of bacteria in biofilms," The Lancet, vol. 358, no. 9276, pp. 135-138, 2001.

[5] T. Bjarnsholt, "The role of bacterial biofilms in chronic infections," Acta Pathologica, Microbiologica et Immunologica Scandinavica, vol. 136, no. 121, pp. 1-51, 2013.

[6] B. LaSarre and M. J. Federle, "Exploiting quorum sensing to confuse bacterial pathogens," Microbiology and Molecular Biology Reviews, vol. 77, no. 1, pp. 73-111, 2013.

[7] E. Cartagena, O. Álvarez Colom, A. Neske, J. C. Valdez, and A. Bardón, "Effects of plant lactones on the production of biofilm of Pseudomonas aeruginosa," Chemical and Pharmaceutical Bulletin, vol. 55, no. 1, pp. 22-25, 2007.

[8] M. Gilabert, A. N. Ramos, M. M. Schiavone, M. E. Arena, and A. Bardón, "Bioactive sesqui- and diterpenoids from the argentine liverwort Porella chilensis," Journal of Natural Products, vol. 74, no. 4, pp. 574-579, 2011. 
[9] M. Gilabert, E. Cartagena, G. Escobar, A. Bardón, and M. Arena, "Volatile terpenoids from water pepper (Polygonum punctatum) against Pseudomonas aeruginosa and Staphylococcus aureus virulence strategies," Global Journal of Agricultural Innovation, Research \& Development, vol. 1, no. 1, pp. 3-10, 2014.

[10] S. Amaya, J. A. Pereira, S. A. Borkosky, J. C. Valdez, A. Bardón, and M. E. Arena, "Inhibition of quorum sensing in Pseudomonas aeruginosa by sesquiterpene lactones," Phytomedicine, vol. 19, no. 13, pp. 1173-1177, 2012.

[11] L. Diblasi, F. Arrighi, J. Silva, A. Bardón, and E. Cartagena, "Penicillium commune metabolic profile as a promising source of antipathogenic natural products," Natural Product Research, vol. 29, no. 23, pp. 2181-2187, 2015.

[12] M. S. Z. Al-Ayed, A. M. Asaad, M. A. Qureshi, H. G. Attia, and A. H. AlMarrani, "Antibacterial activity of Salvadora persica L. (Miswak) extracts against multidrug resistant bacterial clinical isolate," Evidence-Based Complementary and Alternative Medicine, vol. 2016, Article ID 7083964, 5 pages, 2016.

[13] D. J. Mabberley, The Plant Book. A Portable Dictionary of the Higher Plants, Cambridge University Press, Cambridge, UK, 1993.

[14] O. O. A. Lima and R. Braz-Filho, "Dibenzylbutyrolactone lignans and coumarins from Ipomoea cairica," Journal of the Brazilian Chemical Society, vol. 8, no. 3, pp. 235-238, 1997.

[15] U. Steiner, M. A. Ahimsa-Müller, A. Markert et al., "Molecular characterization of a seed transmitted clavicipitaceous fungus occurring on dicotyledoneous plants (Convolvulaceae)," Planta, vol. 224, no. 3, pp. 533-544, 2006.

[16] D. F. Austin, "Merremia dissecta (Convolvulaceae): condiment, medicine, ornamental, and weed: a review," Economic Botany, vol. 61, no. 2, pp. 109-120, 2007.

[17] B. P. Singh and S. Singh, "Chemical investigation of seed of Ipomoea hederacea and its biological activity," Journal of Chemical and Pharmaceutical Research, vol. 4, no. 2, pp. 14411448, 2012.

[18] M. Barnabé, C. H. C. Saraceni, M. Dutra-Correa, and I. B. Suffredini, "The influence of Brazilian plant extracts on Streptococcus mutans biofilm," Journal of Applied Oral Science, vol. 22, no. 5, pp. 366-367, 2014.

[19] M. Hasan, S. Ibrahim, K. Abou El-Seoud, and M. El-Aasr, "Cytotoxic, antioxidant and antimicrobial activities of Ipomoea carnea spp. fistulosa (Mart. ex Choisy) D. Austin," World Journal of Pharmacy and Pharmaceutical Science, vol. 4, no. 6, pp. 12171231, 2015.

[20] R. Joshi, S. Aggarwal, and V. Patni, "Evaluation of anti-microbial activity of in vitro and in vivo plant parts of Merremia dissecta and Merremia aegyptia," International Journal of Pharmaceutical Science and Research, vol. 6, no. 6, pp. 2477-2483, 2015.

[21] D. Srivastava and K. Shukla, "Ipomoea cairica: a medicinal weed with promising health benefits," International Journal of Information Research and Review, vol. 2, no. 5, pp. 687-694, 2015.

[22] P. A. Theng, N. P. Bhosle, A. N. Korpenwar, and N. B. Pandhure, "Phytochemical evaluation and antimicrobial activity of Merremia dissecta (Jacq.) Hallier F. leaf," International Journal of Recent Scientific Research, vol. 6, pp. 2505-2507, 2015.

[23] G. A. O’Toole and R. Kolter, "Flagellar and twitching motility are necessary for Pseudomonas aeruginosa biofilm development," Molecular Microbiology, vol. 30, no. 2, pp. 295-304, 1998.
[24] K. Tateda, R. Comte, J.-C. Pechere, T. Köhler, K. Yamaguchi, and C. Van Delden, "Azithromycin inhibits quorum sensing in Pseudomonas aeruginosa," Antimicrobial Agents and Chemotherapy, vol. 45, no. 6, pp. 1930-1933, 2001.

[25] R. P. Adams, Identification of Essential Oil Components by Gas Chromatography/Mass Spectroscopy, Allured Publishing Corporation, Carol Stream, Ill, USA, 4th edition, 2007.

[26] A. R. Caballero, J. M. Moreau, L. S. Engel, M. E. Marquart, J. M. Hill, and R. J. O'Callaghan, "Pseudomonas aeruginosa protease IV enzyme assays and comparison to other Pseudomonas proteases," Analytical Biochemistry, vol. 290, no. 2, pp. 330-337, 2001.

[27] M. Whiteley, K. M. Lee, and E. P. Greenberg, "Identification of genes controlled by quorum sensing in Pseudomonas aeruginosa," Proceedings of the National Academy of Sciences of the United States of America, vol. 96, no. 24, pp. 13904-13909, 1999.

[28] J. H. Miller, Experiments in Molecular Genetics, Cold Spring Harbor Laboratory Press, Cold Spring Harbor, NY, USA, 1972.

[29] J. Gershenzon and N. Dudareva, "The function of terpene natural products in the natural world," Nature Chemical Biology, vol. 3, no. 7, pp. 408-414, 2007.

[30] M. M. Cowan, "Plant products as antimicrobial agents," Clinical Microbiology Reviews, vol. 12, no. 4, pp. 564-582, 1999.

[31] R. J. Jamasbi and N. M. Taylor, "Correlation between the lipopolysaccharide expression and adhesiveness of clinical isolates of Pseudomonas aeruginosa," Laboratory Medicine, vol. 41, no. 1, pp. 24-30, 2010.

[32] E. A. Parellada, A. N. Ramos, M. Ferrero, E. Cartagena, A. Bardón, and A. Neske, "Effect of the annonaceous acetogenins, squamocin and laherradurin, on the degradation of naphthalene mediated by Pseudomonas plecoglossicida J26," International Biodeterioration and Biodegradation, vol. 72, pp. 82-87, 2012.

[33] V. V. Kravchenko and G. F. Kaufmann, "Bacterial inhibition of inflammatory responses via TLR-independent mechanisms," Cellular Microbiology, vol. 15, no. 4, pp. 527-536, 2013.

[34] D. T. Hughes and V. Sperandio, "Inter-kingdom signalling: communication between bacteria and their hosts," Nature Reviews Microbiology, vol. 6, no. 2, pp. 111-120, 2008.

[35] C. Y. Ragasa, J. Ganzon, J. Hofileña, B. Tamboong, and J. A. Rideout, "A new furanoid diterpene from Caesalpinia pulcherrima," Chemical and Pharmaceutical Bulletin, vol. 51, no. 10, pp. 1208-1210, 2003. 


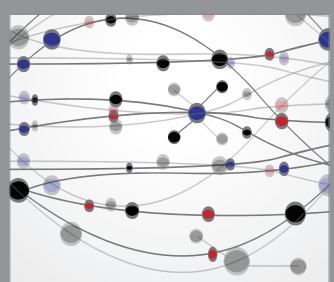

The Scientific World Journal
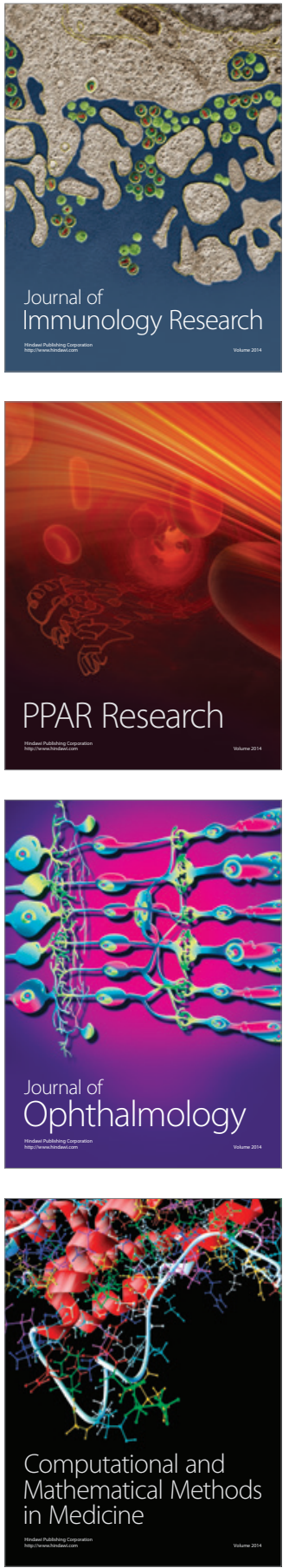

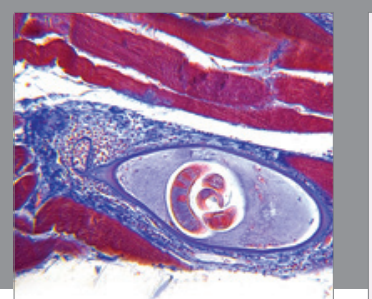

Gastroenterology Research and Practice

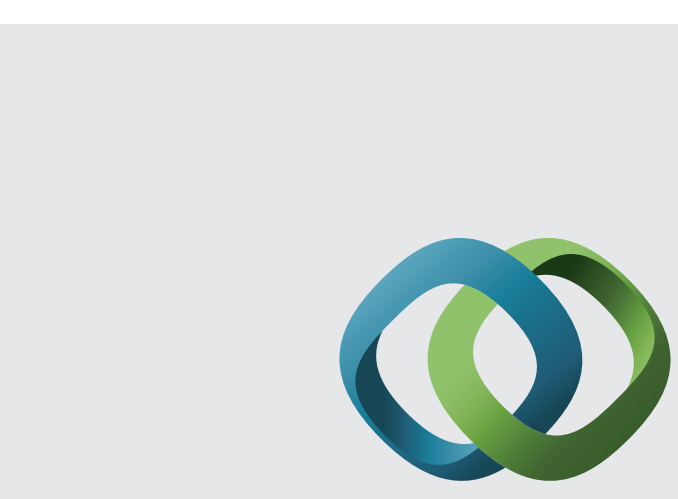

\section{Hindawi}

Submit your manuscripts at

http://www.hindawi.com
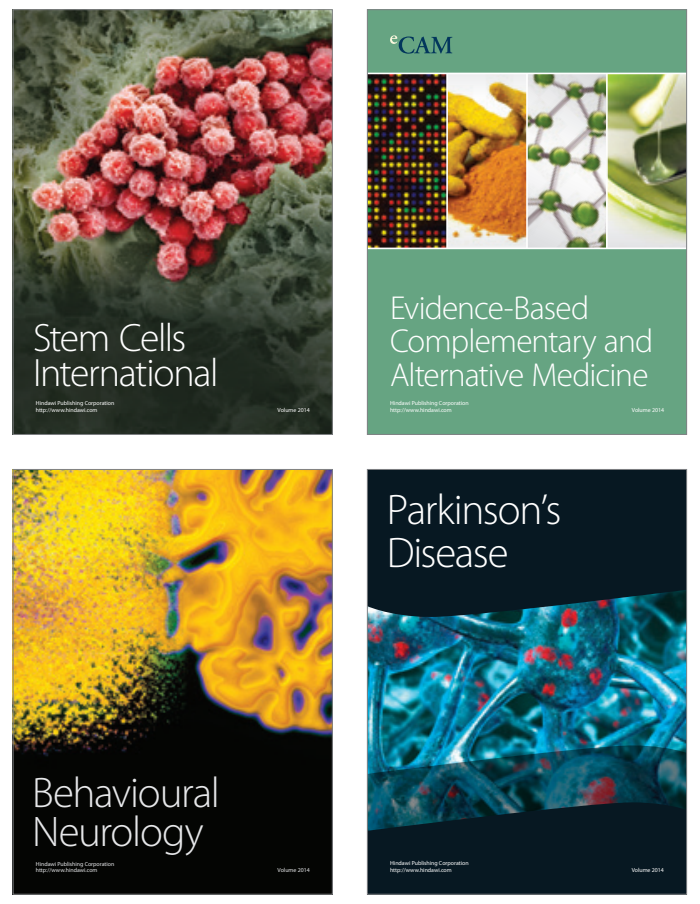
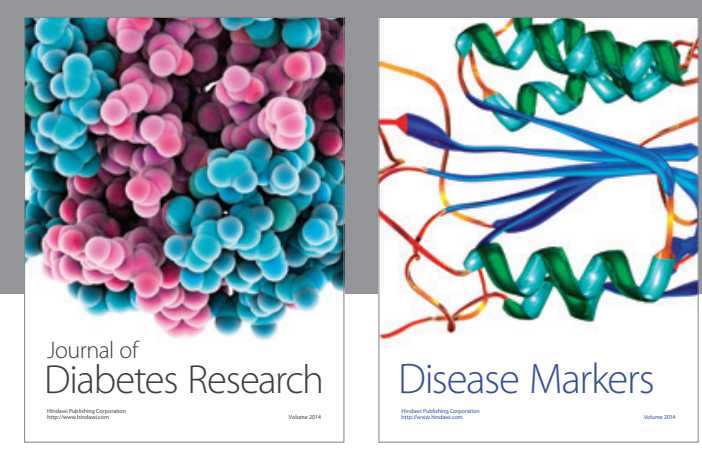

Disease Markers
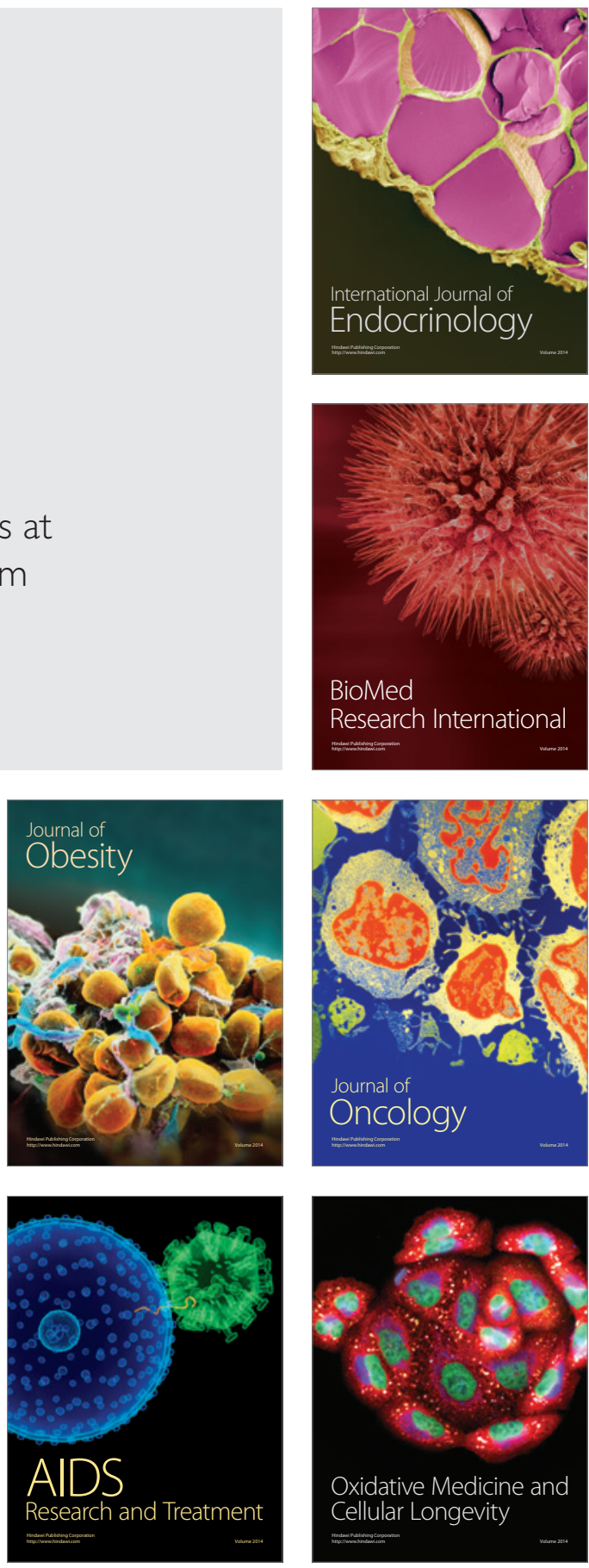